\title{
EL PRIMER FRANCISCO BRINES: LAS BRASAS Y PALABRAS A LA OSCURIDAD
}

\author{
THE FIRST FRANCISCO BRINES: LAS \\ BRASAS AND PALABRAS A LA OSCURIDAD
}

\author{
Antonio Jiménez Millán \\ Universidad de Málaga
}

RESUMEN: El presente trabajo se centra en los dos primeros libros del poeta valenciano Francisco Brines (1932-2021), Las brasas (1960) y Palabras a la oscuridad (1966), haciendo una breve referencia al poema El Santo Inocente, editado en Madrid en 1965 e incluido luego en Materia narrativa inexacta. Establecemos tres apartados: en el primero se estudia el libro Las brasas, premio Adonáis de 1959, un título que ya revela el sentido elegíaco de la poesía de Francisco Brines: alude al rescoldo de un fuego más intenso, que es la vida, y, desde el inicio, se impone la conciencia del desgaste ocasionado por el paso del tiempo. El segundo apartado trata sobre la lectura que hizo Brines de la poesía de Luis Cernuda en el artículo «Ante unas poesías completas", publicado en la revista La Caña Gris (1962), donde se revelan muchas afinidades con el poeta sevillano de la generación del 27. El tercer apartado estudia un libro de poemas mucho más extenso, Palabras a la oscuridad (1966), premio de la Crítica en 1967. Es el libro que contiene más poemas amorosos en la obra de Brines, y paralelamente destacan los viajes y las referencias culturales, afirmándose ya una voz poética que apenas va a experimentar variaciones en los siguientes libros, hasta La última costa (1996).

Palabras clave: Francisco Brines; Luis Cernuda; poesía reflexiva; vitalismo; elegía.

Aвstract:This work deals with the two first books by the Spanish poet Francisco Brines, one of the greatest authors in the second half of the $20^{\text {th }}$ century. These two books are Las brasas (1960) and Palabras a la oscuridad (1966). There will be a slight mention to the poem El Santo Inocente, edited in Madrid (1965) and included later in Materia narrativa inexacta. First, his poetics is studied, starting with the book Las brasas, Adonáis Prize in 1959, a title that reveals Francisco Brines' elegiac sense of the poetry since it alludes to the embers of a more intense fire, which is life itself; and from the very beginning, an awareness of the wear produced by the passing of the time becomes relevant. The second part deals with the critical reading by Francisco Brines on Luis Cernuda's poetry carried out in «Ante unas poesías completas», published in La Caña Gris (1962), where many affinities with the Sevillian poet of the 27 Generation are revealed. The third part focuses on a 
long-size book of poems, Palabras a la oscuridad (1966), Prize of Spanish Criticism (1967). No other book written by Brines includes more love poems. At the same time, travels and cultural references appear constantly. With this book, a poetic voice which will hardly experiment important variations in the next books, until La última costa (1996), is affirmed.

KEY wORDS: Francisco Brines; Luis Cernuda; poetry of experience; vitalism; elegy.

\section{LAS BRASAS (1960). CONSTRUCCIÓN DE UN PERSONAJE FANTASMAL}

El poeta valenciano Francisco Brines (1932-2021), premio Cervantes en 2020, publicó en 1984 una antología (Selección propia, Madrid, Cátedra) con una amplia introducción que titulaba «La certidumbre de la poesía»: me parece un texto imprescindible para el análisis de su poética, ya que él mismo describe con detalle su trayectoria hasta ese momento y se detiene en interesantes cuestiones particulares, desde el origen de su escritura en la edad adolescente hasta los recursos del lenguaje y su manera de entender la poesía, entre la emoción y el conocimiento. En suma, el proceso de creación de sus libros de poemas. Cuando apareció la citada antología, Brines había publicado Las brasas (1960), El Santo Inocente (1965; después se incluiría, a partir de 1974, en Materia narrativa inexacta), Palabras a la oscuridad (1966), Aún no (1971) e Insistencias en Luzbel (1977). En 1974 había reunido por primera vez su poesía completa bajo el título Poesía (1960-1971). Ensayo de una despedida (Barcelona, Plaza y Janés, con un amplio estudio previo de Carlos Bousoño). Faltaban dos libros que iban a culminar su obra poética y alcanzarían un indudable reconocimiento: El otoño de las rosas (1985) y La última costa (1996), además de otros volúmenes antológicos y algún libro con poemas excluidos.

Para Francisco Brines, la poesía es válida cuando logra transmitir una emoción, teniendo en cuenta que la emoción del poeta no tiene por qué diferir de la sensibilidad del hombre común.Y la vida es siempre el punto de partida para la poesía, como el propio autor reconoce en el mencionado prólogo a Selección propia:

Me importa la poesía en cuanto que me importa la vida. De ahí que preste tanta relevancia a mi individualidad, ya que desde ella la vida es experimentada. Soy, por todo ello, un poeta de la intimidad: se trata de iluminar lo oscuro, pues me interesa mi yo secreto de hombre, pero no porque sea nada 
excepcional sino porque es el mío, y es el que mejor se me puede revelar. [...] Los poetas, al hablar de sí mismos, siempre están hablando de los demás. [...] El poema comunica de inmediato un nuevo entendimiento, una inédita comprensión de la vida (Brines, 1984: 42, 46).

$\mathrm{Y}$ un poco antes afirmaba, en el mismo texto, que la poesía «es siempre un dificultoso rescate de la existencia» (Brines, 1984: 23). A tono con estas declaraciones, no es raro que Brines rechace la imagen de la poesía como artificio retórico y que tampoco pueda entenderla como diversión o juego. Como ha escrito Francisco Díaz de Castro:

A lo largo de su escritura, Brines ha ido generando una cre-
ciente reflexión ética en tono menor, el único posible para
hacer comunicable, sin excesos retóricos, la energía de la
búsqueda, la permanente tensión entre el agradecimiento a la
existencia y el dolor de la pérdida (Díaz de Castro, 2011: 48).

Más adelante nos centraremos en esa dualidad constante; interesa ahora seguir analizando ciertos aspectos generales de la poética de Brines que apuntan hacia distintas formas de conocimiento. El poeta valenciano publica sus primeros libros en la década de los sesenta, cuando aún sigue vigente la polémica entre comunicación y conocimiento iniciada unos años antes; es bien sabido que algunas poéticas que se incluyen en la antología Poesía última (1963), de Francisco Ribes, no solo critican los fundamentos de la primera poesía social, sino que profundizan en la línea marcada por Carlos Barral en su texto teórico «Poesía no es comunicación» (revista Laye, 1953).Así, en «Unas notas sobre poesía», Claudio Rodríguez nos dice que la poesía es sobre todo participación, es un modo de conocer la realidad; y para conocer la realidad, la primera exigencia es el abandono de la retórica abstracta y simbólica: por ejemplo, esa retórica que se escondía detrás de la noción de pueblo, tan utilizada por los poetas sociales y, en el fondo, tan abstracta y tan vacía. Por su parte, José Ángel Valente, en un texto titulado «Tendencia y estilo» (que luego incluirá en el libro Las palabras de la tribu), nos habla del formalismo temático de la poesía social, que había conducido a la misma repetición y a los mismos clichés existentes en la poesía religiosa u oficialista de los cuarenta.

Claro está que la poesía entendida como forma de conocimiento parte siempre de la experiencia personal,y de este modo la entiende 
Francisco Brines, incluso cuando aborda un concepto tan ambiguo como el de misterio.Volvamos a «La certidumbre de la poesía»:

En ocasiones el poeta ha tratado de desvelar alguna porción del misterio de la vida, de arañar el enigma a cambio de hallar el apagado resplandor de una significación. [...] La poesía no es un espejo, sino un desvelamiento (Brines, 1984: 14, 17).

Y poco después añade esta precisión:

Hay también otra poesía preferida que es, más que de conocimiento, de salvación. Ella intenta revivir la pasión de la vida, traer de nuevo a la experiencia lo que, por estar vivo, ha condenado el tiempo. El poema acomete esa ilusión de detener el tiempo, de hacer que el instante transcurra sin pasar, efimero y eterno a la vez (Brines, 1984: 18).

La temporalidad es otra clave de la poesía de Francisco Brines; el autor reconoce que la temática temporal resulta más decisiva que la estrictamente amorosa. Podríamos decir que la segunda se halla casi siempre sometida a la primera, que el amor, o el placer, son indisociables del tiempo. En cualquier caso, existe una profunda identificación entre esas dos dimensiones:

El tiempo es mi cuerpo y mi enigma, y también el fracaso definitivo: el amor es mi inserción en el tiempo con la intensidad máxima, el deseo de mi mejor realización posible, y es también un fracaso que, aunque no tan absoluto como el de la mortalidad, puede ser más doloroso (Brines, 1984: 20).

Intensidad es otro concepto de gran relevancia en la poética de Brines, especialmente cuando va asociado a la experiencia erótica: se advierte, sobre todo, en el libro Insistencias en Luzbel (1977).

Según Dionisio Cañas, «Brines, desde el poema que abre la primera sección de su primer libro, Las brasas, crea un personaje fantasmal que habitará en toda su obra: es un hombre sin luz que como ciego percibe la hermosura del mundo que le rodea» (Cañas, 1984: 36). Las brasas (1960, premio Adonáis en 1959) es un título que revela el sentido elegíaco de la poesía de Francisco Brines: es el rescoldo de un fuego más intenso, que es la vida. Llama la atención que un libro escrito antes de los treinta años esté dominado por sensaciones de acabamiento, pero es que, desde el inicio, se impone la conciencia del 
desgaste ocasionado por el paso del tiempo. La primera sección del libro se titula "Poemas de la vida vieja»; el personaje fantasmal al que aludía Dionisio Cañas se imagina a sí mismo con una edad mucho más avanzada y, a partir de esa ficción, nos presenta un contraste entre el mundo nítido y sensual de la costa mediterránea y las impresiones de ausencia y olvido, indisociables de la muerte. En el sexto poema (Brines no les pone título) de la sección inicial aparece un personaje distinto, un visitante:

El visitante me abrazó, de nuevo
era la juventud que regresaba,
y se sentó conmigo. Un cansancio
venía de su boca, sus cabellos
traían polvo del camino, débil

luz en los ojos. Se contaba a sí mismo

las tristes cosas de su vida, casi se repetía en él mi pobre vida.

Arropado en las sombras lo miraba.

La tarde abandonó la sala quieta cuando partió. Me dijo que fue grato vivir con él (la juventud ya lejos), que era una fiesta de alegría. Solo volví a quedar cuando dejó la casa.

Vela el sillón la luna, y en la sala se ven brillar los astros. Es un hombre cansado de esperar, que tiene viejo su torpe corazón, y que a los ojos no le suben las lágrimas que siente (Brines, 1997: 25).

Esa tercera persona enigmática puede implicar el desdoblamiento de la voz poética o, como sugería Carlos Bousoño en el estudio previo a Poesía (1960-1971). Ensayo de una despedida, una forma de objetivación del yo y de identificación con todos los hombres:

¿Qué sentido tiene esa invención brinesca? A mi juicio, se debe, no solo a un intento de objetivar el yo en un soporte aún más alejado de su propia persona, y, por tanto, de mayor pudicia; se debe también, probablemente, a otras dos razones de mayor entidad. Sería la primera de ellas que, puesto que se canta lo común a todos los hombres, el autor se siente identificado con cualquiera de ellos, en cualquier época (de 
ahí la cita que pone Brines al frente de Las brasas: «Alguien ve siempre una muchedumbre de pequeñas brasas.» El poeta es una de esas brasas). La razón complementaria de la precedente radicaría en la intuición de la menesterosidad y progresiva escasez del hombre, en las que el autor se reconoce (Bousoño, 1974: 83).

A partir de esa indeterminación del protagonista, Francisco Brines proyecta su visión elegíaca del mundo, el sentimiento de pérdida que lleva consigo el vivir. En la parte central del libro, «El Barranco de los Pájaros» es un poema extenso dividido en siete secciones. Francisco Brines se vale de la narración alegórica: describe una excursión de jóvenes - niños o adolescentes - que suben a una montaña; en el poema III se encuentran a un leñador que le da un hacha a cada uno, un instrumento que simboliza claramente la violencia y la agresividad (la realidad de la posguerra española está aquí insinuada más que aludida de forma directa). En el poema VII, los jóvenes se han convertido en hombres y al final de la secuencia ya son ancianos que se enfrentan a la desolación:

\section{[...] Con los astros}

se cumple la honda noche, y allí queda

fiel a su soledad, frío en el suelo

(Brines, 1997: 41).

Según el detallado análisis de Carlos Bousoño, se da en «El Barranco de los Pájaros» una combinación de alegoría, simbolización disémica y yuxtaposición temporal que carece de antecedentes en la poesía española (Bousoño, 1974: 61). La tercera parte de Las brasas, "Otras mismas vidas», consta de cuatro poemas que hablan de la pérdida de la inocencia. Si volvemos a la mirada retrospectiva que proyecta el autor en la antología Selección propia, comprobamos un desplazamiento del sentido de lo sagrado: cuando el paso del tiempo le destierra de la infancia ya no le sirven las creencias religiosas, que son sustituidas por el hallazgo de la palabra poética («la fórmula del rezo se hizo verso").Y la poesía se convierte, a partir de ese momento, en una búsqueda de lo sagrado personal:

La relación con lo sagrado, tal como se me había enseñado, se fue haciendo cada vez más distante, y solo se mantenía por aquella nueva vía que la palabra, desde su libertad, alumbraba. [...]. La nueva realidad que, mediante las palabras, hago mía, 
solo me puede ser dada en el texto; y se trata de una revelación que enteramente me pertenece, que no viene de fuera, sino de mi interior secreto y oscurecido (Brines, 1984: 17).

Durante la niñez no existe la conciencia de la muerte, sí una plenitud que se asocia con los espacios naturales y muy especialmente con el mar. Las precisiones en torno a Elca que realiza Brines al final de "La certidumbre de la poesía» giran en torno a la contemplación de la naturaleza ${ }^{1}$; es un espacio abierto al mar que sugiere, a la vez, inocencia y libertad, descubrimiento y goce, tal como se puede intuir en este poema que pertenece a la tercera y última sección de Las brasas:

No existía la muerte: cuánto orgullo feliz. El salto era atrevido, siempre cruzó la viva hoguera pastoril, la que dañaba al monte. En la fuente del olivar sus piernas eran arco de aquel secreto curso, la bebía sin doblar las rodillas, muy gigante. $\mathrm{Y}$ vigilaba el mar, grandes veleros que apenas navegaban. Tras la playa defendía a los huertos de la sal, del miedo de los vientos. Aquel niño puso color al sol, en los balcones lo extendía a vivir despacio. Bello, tanto como un reciente amigo, más aún, enamorado de sí mismo (Brines, 1997: 47).

En contraste con esa plenitud, los espacios urbanos tienen cierta connotación negativa desde el primer libro de Francisco Brines. El siguiente poema de la sección «Otras mismas vidas» nos traslada a Madrid, donde el poeta residiría durante muchos años, y las sensaciones son muy diferentes. Ahora se imponen la soledad, el cansancio, la extraña seriedad: «Mas yo qué solo estoy, Madrid se va / saliéndose a la calle por ver pinos. / Miro la habitación, en el espejo / desvanecida mi figura seria, / ya sin dolor el alma. La fatiga / rinde el cuerpo

1 Se trata de un aspecto fundamental de la poesía de Francisco Brines, hasta sus últimos libros.Véase, por ejemplo, el poema «El niño perdido y hallado (en Elca)», de La última costa (1995). 
del hombre, le da un punto / de paz, lo aleja de la vida libre. / Los bultos que dejó, sus cartas, tocan / mis dedos en silencio, como el campo / la tarde de febrero que se ensancha...» (Brines, 1997: 49).

Como decíamos al inicio, El Santo Inocente se publicó en 1965 y luego se integró, junto con otros dos poemas de esta época, en el apartado Materia narrativa inexacta, que ya aparece en el volumen recopilatorio Poesía (1960-1971). Ensayo de una despedida (1974). Es un poema exento que contiene una acerba crítica a la superstición religiosa y a la moral impuesta, como ha analizado con detalle Duque Amusco (2021). «En la República de Platón» y «La muerte de Sócrates» son poemas narrativos, de actualización histórica, en los que la reflexión adquiere cierto carácter ensayístico (un tono poco frecuente en la poesía de Francisco Brines) y tiende hacia la recuperación de la filosofia estoica e incluso de la enseñanza de Séneca. El primero de ellos, «En la República de Platón», es un buen ejemplo del uso del monólogo dramático, y ello nos lleva directamente a la lectura de Luis Cernuda que realizó Brines a comienzos de la década de los sesenta.

\section{FRANCISCO BRINES ANTE LA OBRA \\ DE LUIS CERNUDA: EL HOMENAJE DE LA CAÑA GRIS (1962)}

En el año 1958, la editorial Fondo de Cultura Económica publica la tercera edición de La realidad y el deseo. No solo la poesía de Cernuda, sino también su obra crítica comienza a tener mayor difusión en España a raíz de la aparición de Estudios sobre poesía española contemporánea (Madrid, Guadarrama, 1957), «Historial de un libro» (Papeles de Son Armadans, XXXV, febrero de 1959) y el primer volumen de Poesía y literatura (Barcelona, Seix Barral, 1960). La antología de José María Castellet Veinte años de poesía española (Castellet, 1960) incluye cinco poemas de Cernuda y el crítico catalán le dedica bastante atención en su polémico y no siempre afortunado estudio previo. Basándose en fragmentos de "Historial de un libro", recién publicado en Palma de Mallorca, Castellet afirma que «Luis Cernuda se nos aparece hoy quizá como el poeta del 27 que más agudamente ha interpretado el proceso sufrido por sus compañeros de generación y, en parte, por él mismo", un proceso que conduce a una expresión más cercana al 
lenguaje coloquial y sigue una tendencia objetivadora relacionada con la experiencia. Según el esquema establecido por Castellet en ese prólogo - tradición simbolista frente a tradición realista-, la poética de Cernuda estaría «totalmente desvinculada de la tradición simbolista, en marcha hacia un realismo que no se reconoce o no quiere reconocerse con ese nombre». Al margen de este juicio evidentemente exagerado, sí acierta Castellet al considerar a Cernuda «uno de los autores del 27 que más cerca se encuentran de muchos jóvenes poetas de hoy que, sobre sus mismas bases formales, buscan sobrepasar esta "poesía de la experiencia individual", añadiéndole una dimensión histórica» (Castellet, 1960: 100). La verdad es que los conceptos de realismo crítico o realismo histórico quedaron pronto desfasados para esos mismos poetas jóvenes a los que se refiere Castellet. Estos autores, agrupados más tarde en la llamada generación de los cincuenta o del medio siglo, modifican sensiblemente los planteamientos de la poesía social sin abandonar el compromiso político que habían defendido Blas de Otero, Gabriel Celaya o Eugenio de Nora: todos ellos desplazan el centro de atención hacia lo privado y, como ha escrito Pere Rovira, «el testimonio social pasa por la consideración crítica de la propia intimidad» (Rovira, 1996: 21). En este sentido se orienta, básicamente, la lectura y asimilación de la poética de Luis Cernuda por parte de los poetas del medio siglo, con una gran variedad de registros y matices.

En el otoño de 1962, la revista valenciana La Caña Gris, dirigida por Jacobo Muñoz, dedica a Cernuda un homenaje en el que participan Vicente Aleixandre, Juan Gil-Albert, María Zambrano, Rosa Chacel,Vicente Gaos, José Hierro, Jaime Gil de Biedma, Francisco Brines, José Ángel Valente, el propio Jacobo Muñoz, José María Castellet, José Olivio Jiménez, Carlos Peregrín Otero y los hispanistas Robert K. Newman y Derek Harris. La interpretación crítica que aportan los poetas del 50 (Gil de Biedma,Valente, Brines) descubre nuevas dimensiones de la obra cernudiana y proporciona, a la vez, claves importantes para entender el cambio de perspectiva que se produce en la poesía española de posguerra.

La aportación de Francisco Brines al homenaje de La Caña Gris, "Ante unas poesías completas», es bastante más extensa que las de otros compañeros de generación (Jaime Gil de Biedma, Valente). Según el criterio de Brines, Aleixandre, Prados y Cernuda ofrecen lo mejor de su obra en los años posteriores a la guerra civil; en el caso de Cernuda, Las nubes señala el cambio hacia una segunda etapa de su poesía, caracterizada, sin embargo, por una profunda unidad: 
«La unidad de esta obra se nos revela en una constante: Cernuda es siempre un poeta de la realidad» (Brines, 1995: 74). Otras constantes serían la soledad ("A ninguno debes tanto como a la soledad», escribe Cernuda en Ocnos) y la conciencia dramática del tiempo, indisociable del conflicto entre realidad y deseo.Va desvelando Brines las claves de la poesía cernudiana a través de un detenido análisis de cada uno de sus libros. El núcleo temático de la primera época —el deseo físico, el paso del tiempo, la belleza, la soledad, la indolencia - se ajusta a las distintas modalidades que configuran la ideología literaria de los años veinte y treinta, cuando la poesía pura y los proyectos renovadores de la tradición (Égloga, elegía, oda) son desplazados por una rebeldía de signo surrealista (Un río, un amor; Los placeres prohibidos): otra vez la radical soledad del hombre enfrentado con el mundo. En la breve colección Donde habite el olvido y en el posterior Invocaciones se pone de manifiesto la importancia que tenía para Cernuda la experiencia vital, intensificada a partir de Las nubes. Brines recoge de «Historial de un libro" y de Estudios sobre poesía española contemporánea algunas citas muy reveladoras: «Lo que el poeta expresa en sus versos es la experiencia de la vida» (Estudios...); o bien: «Creo que es necesidad primera del poeta reunir experiencia y conocimiento, y tanto mejor mientras más variados sean» («Historial de un libro»). Brines coincide con José Ángel Valente y Jaime Gil de Biedma a la hora de resaltar determinados aspectos de la poética cernudiana: el nuevo enfoque de temas clásicos, el talante meditativo, el conocimiento de la poesía inglesa, la densidad y la concentración expresiva, la forma de incorporar la tradición a su propia poesía. Muchos años más tarde, otro gran poeta de la generación de los cincuenta,José Manuel Caballero Bonald, iba a relacionar estrechamente la poética de Luis Cernuda con la de Francisco Brines en lo que supone para ambos la incorporación de la experiencia:

Desde su libro inicial, Las brasas, ya anunciaba Brines una poética cuya ruta no ha hecho sino decantarse a lo largo de los años, sin apenas modificar su procedencia ni su destino. Una poesía sosegada, sin debilidades apreciables, de elegante elocución, de frecuentes destellos reflexivos, asentada en la vida; una poesía que a medida que describe la realidad va abriéndole otras salidas a la realidad. Lo que el texto saca a flote es propiamente el sedimento esencial de la experiencia, sin que en ningún momento queden registrados sus excedentes ocasionales (Caballero Bonald, 2019: 419). 
Al incidir sobre la aceptación cada vez mayor de la obra de Cernuda, Brines aporta un inteligente comentario cuya validez resulta hoy indiscutible: la poesía no tiene público, a diferencia de la novela, pero sí lectores ( $« \mathrm{El}$ pueblo, en nuestro tiempo, no lee ni escucha poesía. Pero sí hay lectores de poesía; más de los que se cree, aunque siempre menos de los deseados» [Brines, 1995: 89]) y el primer lector con quien debe sentirse obligado un poeta es él mismo (justamente la actitud que siempre mantuvo Luis Cernuda). Ese grado de exigencia le permite a Brines realizar, de soslayo, algunas críticas a la poesía social, al equívoco de la «inmensa mayoría» y a la confusión del lenguaje coloquial con el «deliberado prosaísmo». Ya en la década de los ochenta, en el tantas veces citado «La certidumbre de la poesía», Brines vuelve a tratar la cuestión de los lectores y el público:

El problema, se me podría decir, es la necesidad de conquistar un público, mas yo no creo que exista un público sino lectores, a los que hay que persuadir con los poemas, y aquéllos no tienen por qué componerse de muchos. Una de las ventajas que todavía acompaña a la poesía es esta ausencia de público y, por tanto, de publicidad (Brines, 1984: 43).

Hablaba Gil de Biedma de una afinidad de temperamento poético entre Cernuda y Brines (Gil de Biedma, 2017: 502). Esa proximidad se observa a través del ensayo incluido en La Caña Gris tanto como en su poesía y en las reflexiones posteriores de Brines acerca de su propia escritura. En el texto de 1962 destaca el poeta valenciano la abundancia de poemas autobiográficos en la obra de Cernuda y, al mismo tiempo, su tendencia a la objetivación; en efecto, a finales de los cincuenta, la poesía y la crítica literaria de Cernuda han alcanzado cierto nivel de objetivación (a pesar de algunas arbitrariedades) y, por ejemplo, en un ensayo de 1959 Cernuda admira en Baudelaire la perfección de la obra, un resultado, una solución a los conflictos interiores del poeta, no ya la raíz satánica de la poesía ni la actitud vital de los malditos, como ocurría en los años treinta. Esa distancia reflexiva se proyecta hacia la crítica social, hacia la censura de la ignorancia y la soberbia: una línea que seguirá Brines en las sátiras de Aún no (1971). Pero hay coincidencias más profundas, y son aquellas que se refieren a la finalidad de la poesía: desvelar el mundo, decir su verdad oculta, ver la unidad de la vida. En el prólogo a Selección propia, Brines afirma que «la poesía no es un espejo, es un desvelamiento", una manera de acercarse al misterio de la vida, 
y que el poema presenta «la conciencia dramática del vivir». Según sus propias palabras, el conjunto de la obra de Francisco Brines no es más que una extensa elegía que parte de la ilusión de detener el tiempo, «de intentar revivir la pasión de la vida», «de hacer que el instante transcurra sin pasar, efimero y eterno a la vez» (Brines, 1984: 18). La conciencia de las sucesivas pérdidas en que consiste el vivir configura, en la poesía de Brines, un repertorio de símbolos que incluye la sombra, la ceniza, la oscuridad, la noche. Ya hemos dicho que el título de su primer libro, Las brasas (1960), nos lleva hacia la dimensión simbólica del rescoldo, del fuego desvanecido. Momentos de intensidad vital recordados desde la lucidez, viajes hacia el pasado que propician una contemplación melancólica: son argumentos del siguiente libro, Palabras a la oscuridad (1966); sin embargo, esa mirada también implica una exaltación constante del mundo, de la belleza y de la vida desde la certeza de la fugacidad («Nunca será olvidable este momento», leemos en el poema «Balcón en la sombra»). La simultaneidad del estoicismo y del goce, tan característica del vitalismo cernudiano, está muy presente en Brines, como puede verse en el poema "Oscureciendo el bosque», de Palabras a la oscuridad:

Toda esta hermosa tarde, de poca luz, caída sobre los grises bosques de Inglaterra, es tiempo.

Tiempo que está muriendo

dentro de mis tranquilos ojos, mezclándose en el tiempo que se extingue.

Es en la vida todo transcurrir natural hacia la muerte, y el gratuito don que es ser, y respirar, respira y es hacia la nada angosta.

$[\ldots]$

Mirad con cuánto gozo os digo que es hermoso vivir

(Brines, 1997: 133-134).

En Palabras a la oscuridad se encuentra «La mano del poeta (Cernuda)", un homenaje estructurado en tres secciones a partir de la evocación de un museo y la posterior asociación a la figura del poeta (y a su estancia en Cambridge, donde se sitúa el poema de Brines), que termina en un canto a la esperanza de sobrevivir: 
Y a pesar del dolor y la amargura del alentar humano defendiste la vida con amor, y con amor la muerte: aceptaste un destino rencoroso.

[...]

$\mathrm{Y}$ vi tu mano muerta en el viaje

que me llevaba a la ciudad donde viviste

sin tierra y sin amor,

con el deseo sólo del amor y la tierra.

Y percibí que el mundo estaba oscuro, más allá de los faros.

Con sequedad nacida de un grave pensamiento

seguí trenzando el hilo del futuro:

mientras la vida alienta, el hombre quiere

mirar la muerte expuesta

en aquello que, un tiempo, retuvo en sí la vida,

para pensar que no se acaba completamente todo;

así procura vida la memoria

en el informe bulto de la muerte (Brines, 1997: 141).

No podemos olvidar que en la poesía de madurez de Luis Cernuda domina una conciencia trágica del tiempo, el recuerdo dramático de la belleza y la juventud perdidas. Los dos últimos libros publicados por Francisco Brines, El otoño de las rosas (1986) — dedicado a sus dos maestros reconocidos: Juan Ramón Jiménez y Luis Cernuda- y La última costa (1995), participan de ese sentimiento, aunque la presencia del tiempo destructor no excluye la celebración de la vida por "el secreto entusiasmo de haber sido». A propósito de Brines, José Olivio Jiménez resalta «la indiscutible universalidad de su canto hondamente elegíaco, en el que, a un tiempo, el hombre se empeña en afirmar su débil realidad y la hermosura del mundo y de la vida» (Jiménez, 1986: 8). Y, más recientemente, Luis García Montero afirma que la poesía de Francisco Brines trasmite «un sentido de la dignidad humana que tiene que ver con una forma concreta de concebir la poesía» (García Montero, 2010: 15).

Al escribir sobre la pintura de Ramón Gaya —muy próximo a Luis Cernuda enValencia, durante la guerra civil-, Francisco Brines afirmaba que la misión del artista consiste en «salvar para la emoción el curso temporal, cotidiano, del hombre que se es» (Brines, 2001:14). En más de una ocasión, Francisco Brines se ha referido a la «claridad de la palabra»: con la poesía, "una invisible luz», se trata de iluminar lo oscuro (un proyecto que estaría en la base del título Palabras a la 
oscuridad, como veremos a continuación) ${ }^{2}$. En el poema «Resumen fantástico", de Insistencias en Luzbel, se atisba la salvación a través de las palabras:

Hemos quemado muchos cigarrillos, y así se fue la vida.

Largas conversaciones, y trabajos mezquinos. También breves sollozos, y sucesión de cuerpos.Y esos sordos sermones insistentes. Alguna vez fue bella.

Escogimos unas pocas palabras que pudieran salvarla, y este mal resultado: así retiene la mirada un rostro fugitivo. Hoy, que ya se ha marchado, queda solo esta duda: no sé si se fue rápida o demasiado lenta. $\mathrm{Y}$ algo que no he entendido: hubo muchos bostezos (Brines, 1997: 344).

Al final se impone el tedio de manera rotunda, negando cualquier posibilidad de salvación. Pero estamos hablando ya de Insistencias en Luzbel, publicado en 1977; habría que retroceder más de una década para fijarse en el libro anterior, clave en la trayectoria de Francisco Brines.

\section{MEMORIA DEL AMOR Y LOS VIAJES: PALABRAS A LA OSCURIDAD (1966)}

Premio de la Crítica en 1966, Palabras a la oscuridad (Madrid, Ínsula, 1966) es mucho más extenso que Las brasas. Dividido en siete secciones, el libro parte de una mirada sobre la tierra natal como ámbito de afirmación. Según José Olivio Jiménez, que le dedicó un estudio relativamente amplio, la ordenación de los poemas «se mueve desde

2 En «Certidumbre de la poesía» encontramos una precisión muy interesante sobre la claridad y el hermetismo: «Así he procurado siempre no oscurecer el texto, sino conseguir la máxima claridad, sin que esto pudiera justificar nunca la simplificación o el empobrecimiento del poema. Si la experiencia que se revela es compleja, y en principio oscura, el poema acusará esta dificultad, pero con voluntad siempre (y esto con el máximo rigor) de lograr una expresión lo más clarificadora posible. De ahí que mi lucha por el lenguaje sea por hallar la mayor lucidez expresiva, lo que me obliga a buscar la precisión de la palabra» (Brines, 1984: 40). 
lo más firme a lo más negativo; de lo cercano, seguro y entrañable a lo arcano y desconocido [...]; de la luz y la tierra, [...] a la ceniza, la sombra y el humo» (Jiménez, 1972: 178). Encontramos apuntes descriptivos de lugares, breves evocaciones de anécdotas vividas o contempladas; los momentos de especial intensidad vital contrastan con el deterioro que ocasiona el paso del tiempo.

El poema «Después de la infancia», en la sección inicial, constata la imposibilidad del regreso a aquella etapa feliz en la que se sentía el misterio de otra forma: «He querido sentir, / de nuevo, aquel misterio / de la emoción del mundo, / y en el mismo lugar / esperé a las tinieblas. / Altas aparecieron / las luces vacilantes de los astros, / y el pecho no tembló. // El tiempo, en su tarea, / lleva el polvo a las cosas, / despoja de secretos a los hombres, / en el alma se queda / germinando» (Brines, 1997: 76-77). El recuerdo se vincula ahora con más fuerza a la primera persona («Vísperas y memorias», «Sombras en un valle») y ya aparece una luz gastada que no es propia de la noche sino del tiempo, con todo su poder destructivo («Nocturno del joven»), perceptible también en el extenso poema «Entra el pensamiento en la noche» («El agua se ha callado. Dice el hombre: / es el tiempo quien quiebra la alegría» [Brines, 1997: 89]).

La segunda sección introduce el tema del viaje, fundamental en este libro ${ }^{3}$, pero también numerosas referencias culturales en poemas como «Museo de la Academia», «Plaza en Venecia» o «Versos épicos (Virgilio en Trápani)», donde Brines recurre de nuevo al monólogo dramático para abordar otra reflexión en torno a la escritura y a la relación erótica:

No imagino un suceso desusado

para cantar con elevado tono, con acento

de llama, vuestra amorosa historia;

es muy baja mi voz (Brines, 1997: 112).

3 En una conversación con Alejandro Duque Amusco, Francisco Brines relacionaba el proyecto de composición de Palabras a la oscuridad con el mito de Ulises: «Nunca he podido escribir un poema siguiendo una pauta determinada. Ni siquiera cuando he visto con claridad un posible itinerario para el libro, como me ocurrió con los poemas de Palabras a la oscuridad mientras los estaba escribiendo. Pensé que el libro podría seguir un recorrido como el de Ulises. Un Ulises de hoy, en el que Ítaca no es un lugar, sino un espacio mítico que simboliza distintas cosas: la infancia, la salida al mundo, el amor, el dolor, etc., y que hubiera al final un regreso. Pues no» (Duque Amusco, 2021: 41-42). 
En la tercera sección del libro se integran dos poemas extensos, «La piedra del Navazo» y «El caballero dice su muerte». Los dos se proyectan hacia el pasado, de distinto modo: fortalezas, remotas batallas, armas y emblemas contribuyen a una recreación histórica en la que surgen personajes fantasmales, condenados a un eterno exilio. Muy diferente es la sección IV, que recoge poemas escritos en Inglaterra (Brines estuvo dos años como lector en Oxford), poemas en los que se advierten contrastes muy marcados: si en "Oscureciendo el bosque» se nos da una imagen de plenitud tras la contemplación serena del paisaje - ya nos referimos antes a este poema-, hay otros momentos en los que se impone una sensación de irrealidad y extrañeza, visible en «Evocación en presencia», «Ceniza en Oxford» o «Palacio del Otoño». Acerca del protagonista de estos poemas escribe Alejandro Duque Amusco: «No es extranjero porque vaya viajando por el mundo [...], sino que seguirá sintiéndose extranjero aun en su propia tierra, donde tan hincadas tiene las raíces, porque para él la extranjería no es otra cosa que ser un extraño en el mundo y su peregrinaje una manera esencial de entender la vida: un pasar, un fluir incesante» (Duque Amusco, 2021:61). Otros poemas de este apartado, como «Mere Road» o el ya comentado «La mano del poeta (Luis Cernuda)", vuelven sobre el deseo, la soledad y la memoria, mientras que «Otoño inglés» refuerza la idea vitalista de la belleza del mundo y, a la vez, el sentimiento de pérdida:

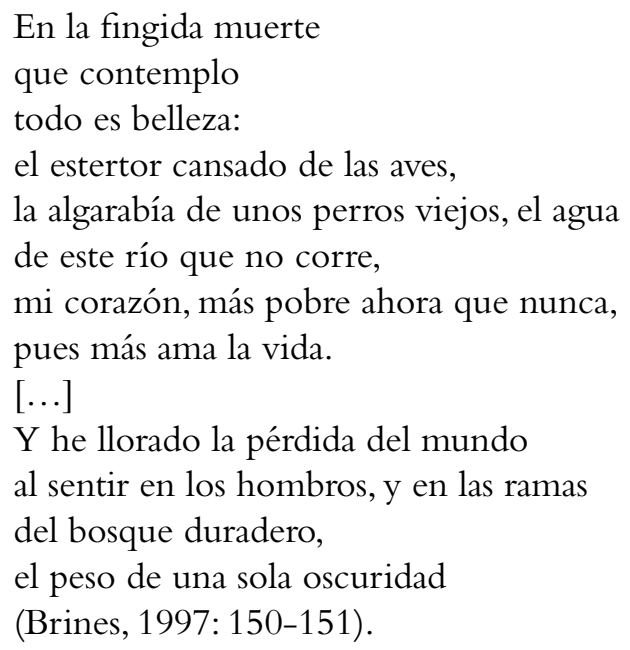

Sobre esta constante dualidad iba a reflexionar Brines, años después, en «La certidumbre de la poesía»: 
En lo que a mí se refiere, los aspectos felices de la vida no son cantados nunca, o apenas, desde su inmediato goce; así como los momentos exultantes del amor, o la participación de la alegría, son acontecimientos prestigiosos que, en mi poesía, solo aparecen desde su pérdida (Brines, 1984: 31).

En este sentido, es importante señalar que en Palabras a la oscuridad hay una indagación en la realidad que intenta llegar más allá de las apariencias y conecta con el misterio ${ }^{4}$. Todo ello afecta muy directamente a las relaciones amorosas, tema central de la sección $\mathrm{V}$. El recuerdo de la intensidad vuelve a situarse ahora en primer plano, cuando el protagonista de los poemas tiende a reconocerse en el otro. «Este sí es el más hermoso territorio...! Pero esta tierra es fugitiva», dice la frase introductoria de esta sección V (todos los apartados llevan al inicio un texto en prosa, más o menos breve), anticipándose a la dialéctica placer / fugacidad / engaño y vacío que domina los poemas amorosos de Brines: «El velo del amor», "Aceptación en la terraza» ( $\mathrm{Y}$ al dolor agradeces / que se desborde de tu frágil pecho / la firme aceptación de la existencia» [Brines, 1997: 158]), «La sombra rasgada», «Desterrado monarca» y, especialmente, «Todos los rostros del pasado" y "Balcón en sombra», donde aparece de forma nítida el contraste entre los momentos de plenitud y la constatación del vacío: «Nunca será olvidable este momento / porque nunca la dicha es olvidable / si ha dejado en el cuerpo tanta fuerza, / fuerza para vivir, fuerza para dar vida. / Pude nacer sólo por esto. / [...] / Ya están secas las rosas, / y el color, que es su tiempo, lo han perdido. / [...] / La miseria del hombre se advierte en este signo: / los ojos están húmedos; / ruin es la expresión del dolor y la dicha, / y ella nos manifiesta, / con su igualdad, la confusión del hombre, / nos enseña en la vida sucesos de la muerte» (Brines, 1997:169, 170-171).

En el conjunto de la obra de Francisco Brines, Palabras a la oscuridad es el libro que más poemas eróticos reúne. Lo ha analizado con acierto José Andújar Almansa:

El erotismo será la otra gran experiencia definitiva para el sujeto de Palabras a la oscuridad. Desde la perspectiva que configura la construcción de una biografia poética, dicha experiencia del amor nos remite en la sección $V$ de la obra a

4 Véase el análisis que, sobre este aspecto, lleva a cabo José Olivio Jiménez (1972: 182-183). 
un acontecimiento concreto, el testimonio de una relación amorosa vivida por el autor en los años coincidentes con la escritura del libro y que habría de convertirse en referente literario y biográfico fundamental para el yo de los poemas (Andújar Almansa, 2003: 62).

El erotismo siempre está en relación muy directa con el tiempo, o más exactamente con el instante, cuya importancia en la poesía de Brines ya destacaba Carlos Bousoño en su estudio de 19745. Los dos últimos poemas de la sección $\mathrm{V}$, «Causa del amor» $\mathrm{y}$ «Un rastro de felicidad", representan una afirmación vital que acepta la imperfección y el dolor ("y busco un rostro que refleje luz, / alguien que como yo, teniendo muerte sólo, / tenga también, como tuviera yo, / venciéndola, la vida» [Brines, 1997: 183]).

En la evocación de la experiencia amorosa, que en algún momento es considerada como la única manera de dominar a la muerte, se insertan los viajes y las referencias culturales (véanse, dentro de la secciónV, «Amor en Agrigento», «Tera», «SS.Annunziata (Brunelleschi)»), argumento central de "Relato superviviente», largo poema que constituye por sí solo la secciónVI del libro y refleja momentos vividos en Delfos, París, Salzburgo, un lago alpino, Ferrara, Corfú y Oxford. El título implica cierta visión pesimista, cuando la vida se ha convertido en mera supervivencia ( Ocasiones de amor / o de dolor que, con firmeza, / me irán envejeciendo» [Brines, 1997: 191]).

La séptima y última sección de Palabras a la oscuridad incluye poemas de temática diversa, pero se intensifica en ellos la dialéctica luz / oscuridad, que no deja de estar presente en todo el libro, empezando por el título.Y, a través de esa dialéctica, hemos de destacar la importancia de la mirada. Al abordar la obra poética de Francisco Brines, Dionisio Cañas establece en su estudio Poesía y percepción (Francisco Brines, Claudio Rodríguez y José Ángel Valente) una similitud entre percepción, mirada y poesía; en el caso de Brines, es una mirada profundamente elegíaca:

«El instante irrepetible de la conciencia, en relación con el instante, también irrepetible, del mundo exterior, se constituirá, pues, como el tema fundamental de esta poesía, precisamente, repito, porque se trata de una estética realista que ama lo concreto, o sea, lo que aparece, por definición, en un aquí y en un ahora» (Bousoño, 1974: 69). 
La mirada en la poesía de Brines parece aspirar a poseer el don totalizador y la habilidad de fijar el mundo en sus momentos más luminosos o plenos. Naturalmente, la dispersión y la fugacidad - que son los elementos que la temporalidad arroja sobre el mundo - serán entonces sus enemigos más frecuentes (Cañas, 1984: 24-25).

Y pone como ejemplo el poema «La última estación de los sentidos», de Aún no (1971):

Veo venir la luz, y los ojos gastarme con piedad, pues quien desvela la realidad es ella, no el asombro.

Y ahí está el firmamento, huestes de luces que combaten en un espacio transparente; el mar

y los desnudos, la carrera y las rosas, el perro negro y la saliva, el cadáver y el llanto, el naranjo y la abeja, el rostro reposado y la sonrisa (Brines, 1997: 285).

Ya desde los primeros poemas de Francisco Brines cobra una gran importancia el aspecto visual, como él mismo reconocía en el prólogo a Selección propia: «En mi caso, la imaginación es primordialmente visual, tanto si su ejercicio se dirige a la luz del mundo exterior, para celebrarlo o interrogarle, como si se dirige a la oscuridad interior, en pos de su desvelamiento" (Brines, 1984:35). Remitimos de nuevo al estudio de Dionisio Cañas: «Una mirada mental puede crear espacios para la imaginación, aunque sean formados a base de una realidad leída (no vivida), o vista a través de una pintura o simplemente inventada» (Cañas, 1984: 30). Así, el balcón, la terraza o el jardín, lugares que se ajustan a los lugares vividos, a la experiencia real, y son ámbitos de la contemplación ya desde Las brasas y Palabras a la oscuridad: «a ese balcón se asomó el niño que inocente inaugura su visión, el joven envejecido antes de tiempo, el maduro personaje que se desdobla para verse a sí mismo» (Cañas, 1984:36).

A veces, los recuerdos nos llevan a pasajes sombríos y la descripción de la realidad enlaza con las imágenes de la España negra que pintaron Goya o Gutiérrez Solana. Es lo que ocurre con el poema «El mendigo», que figura en la sección VII de Palabras a la oscuridad: 
Extraño, en esta noche, he recordado una borrada imagen. El mendigo de mi niñez, de rostro hirsuto, torna desde otro mundo, su mirada dura. Llegaba al mediodía, y un gruñido de animal viejo le anunciaba.

$[\ldots]$

\section{Andaba el niño}

con temor a la puerta, y en su mano depositaba una moneda. Era hosca la voz, los ojos fríos de odio, y sentía un gran miedo al acercarme, la piedad disipada (Brines, 1997: 206-207).

La presencia de esta figura y el tono siniestro con que la evoca Brines me recuerda algunos fragmentos de la obra de Salvador Espriu, desde El caminant i el mur hasta el Llibre de Sinera, donde es frecuente la presencia de los mendigos (captaires) en el penoso ambiente de la posguerra española.Ya al final de Palabras a la oscuridad, no podemos dejar de lado las consideraciones sobre la condición humana en «Muros de Arezzo», ni el final rotundo de «Palabras aciagas», el poema con el que se cierra el libro:

En la soledad has escrito estas palabras

y estás ardiendo:

húndelas en la oscuridad

(Brines, 1997: 215).

Acerca de estos primeros libros publicados por Francisco Brines, me parece muy acertado el balance que hizo Francisco Díaz de Castro:

Desde Las brasas hasta Aún no (1971) se consolida una reflexión sobre las emociones, de estirpe barroca, en la que la creciente presencia de las referencias culturales y la diversidad de los espacios no hace sino corroborar las enseñanzas que el protagonista de esta poesía ha descubierto en las cosas y en los comportamientos (Díaz de Castro, 2011: 48). 


\section{BIBLIOGRAFÍA}

Andújar Almansa, José (2003). La palabra y la rosa. Sobre la poesía de Francisco Brines, Madrid, Alianza Editorial.

BousoÑo, Carlos (1974). «Situación y características de la poesía de Francisco Brines», prólogo a Francisco Brines, Poesía (1960-1971).

Ensayo de una despedida, Barcelona, Plaza y Janés, pp. 9-94.

Brines, Francisco (1974). Poesía (1960-1971). Ensayo de una despedida, ed. Carlos Bousoño, Barcelona, Plaza y Janés.

— (1984). «La certidumbre de la poesía», prólogo a Francisco Brines, Selección propia, Madrid, Cátedra, pp. 13-53.

— (1986). Antología poética, ed. José Olivio Jiménez, Madrid, Alianza Editorial.

— (1995). «Ante unas poesías completas», en Escritos sobre poesía española

(De Pedro Salinas a Carlos Bousoño), Valencia, Pre-Textos, pp. 73-125.

— (1997). Ensayo de una despedida. Poesía completa, Barcelona, Tusquets.

— (2001). «Un solo Gaya», introducción a Algunos

poemas de Ramón Gaya,Valencia, Pre-Textos.

— (2010). Yo descanso en la luz. Antología, Madrid,Visor.

Caballero Bonald, José Manuel (2019). «Francisco Brines», en Examen de ingenios, Barcelona, Seix Barral.

Cañas, Dionisio (1984). «La mirada crepuscular: Francisco Brines», en Poesía y percepción (Francisco Brines, Claudio Rodríguez y José Ángel Valente), Madrid, Hiperión, pp. 23-80.

Castellet, José María (1960). Veinte años de poesía española, Barcelona, Seix Barral.

Díaz de Castro, Francisco J. (2011). «Sobre la poesía última

de Francisco Brines", Ínsula, 775-776, pp. 48-50.

Duque Amusco, Alejandro (2021). Cenizas y misterio. Escritos sobre Francisco Brines, Sevilla, Renacimiento.

García Montero, Luis (2010). «La serenidad poética de Francisco Brines», prólogo a Francisco Brines, Yo descanso en la luz. Antología, Madrid,Visor, pp. 15-24.

Gil de Biedma, Jaime (2017). «Como en sí mismo, al fin», en El pie de la letra. Ensayos completos, Barcelona, Lumen.

Jiménez, José Olivio (1972). «Realidad y misterio en Palabras a la oscuridad (1966), de Francisco Brines», en Diez años de poesía española (1960-1970), Madrid, Ínsula. 
— (1986). Prólogo a Francisco Brines, Antología poética, Madrid, Alianza Editorial.

Rovira, Pere (1996). «Realismos de postguerra», en Los poemas necesarios,

Palma de Mallorca, Universitat de les Illes Balears, pp. 15-29. 